\title{
Pyramidal Tract and Bundle of Bagley in the Goat
}

\author{
By \\ Akira Tokunaga, Katsumi Otani and Jinzo Yamada \\ The Third Department of Anatomy, School of Medicine, Chiba University, \\ 1-8-1, Inohana, Chiba 280, Japan \\ - Received for Publication, October 14, 1975-

\section{Introduction}

In ungulates, very little is known about target areas of the fibers arising in the sensori-motor cortex. King ${ }^{7,8)}$ and $\mathrm{Bagley}^{8)}$, using the Marchi method, independently reported on projections from the cortical areas which they identified as motor areas by histological and/or electrophysiological methods. Besides the pyramidal tract, the latter author ${ }^{\text {s) }}$ described that a cortico-tegmental tract (bundle of Bagley) descended through the midbrain and the pontine tegmentum after leaving the cerebral peduncle at the rostral mesencephalon.

Recently, Haartsen and Verhaart ${ }^{5}$. investigated the pyramidal and Bagley's tracts in detail using the Nauta method in the goat. Verhaart ${ }^{13)}$ claimed in his monograph that Bagley's bundle was commonly found in ungulates, except for the tubulidentata. He also pointed out that the tract of Bagley was very conspicuous only in artio- and perissodactyla.

In previous reports on sheeps and goats, no authors have dealt with the projections from the sensori-motor cortex to the upper brain stem. In this study, we examined the corticofugal fibers arising from the anterior and posterior sigmoid gyri to the brain stem and further down to the spinal cord in the goat with the Nauta-Gygax method.

\section{Materials and Methods}

Six goats and kids, weighing from 6.7 to $34 \mathrm{~kg}$, were used. Large as well as small lesions were made in the anterior and posterior sigmoid gyri with a small blunt surgical knife, avoiding an accidental damage of large blood vessels (Fig. 1). In the cases of G-8, 10, 12 and 13 almost the entire dorsal surface of the gyri was removed, while in G-1 a small lesion was made in the lateral part of the middle anterior sigmoid gyrus, and in G-4 a narrow strip of this cortical area was removed. 
The strip extended from the rostral tip of the suprasylvian gyrus to both sigmoid gyri facing the middle of the cruciate sulcus. Moreover, the gyrus proreus was also involved in the cases of G-10 and 13. After 7 or 14 days, the animals were perfused with $10 \%$ formalin through the heart. The brains and the spinal cords were cut transversely in frozen section at $30 \mu$. Usually every fifteenth section was impregnated by the Nauta-Gygax method ${ }^{18}$.

\section{Results}

In the goat, degenerating corticofugal fibers impregnated with the Nauta-Gygax method mainly consisted of fine granular fragments. In the two-week survival group, we found somewhat better impregnation than in the one-week survival group.

Since the course and termination of the degenerating fibers resulting from the removal of the sigmoid gyri show a substantially similar pattern, regardless of the size of the lesion, the findings of G-12 will be described in this paper as representative of the projections.

\begin{tabular}{|c|c|c|c|}
\hline \multicolumn{4}{|c|}{ Abbreviations } \\
\hline B : & Bundle of Bagley & NA: & Nucl. ambiguus \\
\hline B C I : & Brachium colliculi inferioris & NC : & Nucl. cuneatus \\
\hline $\mathrm{C} \mathrm{C}:$ & Crus cerebri & NCA: & Nucl. cuneatus accessorius \\
\hline C GM : & Corpus geniculatum mediale & NFL: & Nucl. funiculi lateralis \\
\hline C I : & Capsula interna & NG : & Nucl. gracilis \\
\hline $\mathrm{CM}:$ & Nucl. centromedianus & NRT : & Nucl. reticularis tegmenti \\
\hline $\begin{array}{l}\text { CO I : } \\
\text { D P : }\end{array}$ & $\begin{array}{l}\text { Colliculus inferior } \\
\text { Decussatio pyramidum }\end{array}$ & NTS VC: & $\begin{array}{l}\text { Nucl. tractus spinalis } n \text {. } \\
\text { trigemini caudalis }\end{array}$ \\
\hline $\begin{array}{l}\mathrm{EP}: \\
\mathrm{F} \text { L } \mathrm{P}\end{array}$ & $\begin{array}{l}\text { Epiphysis } \\
\text { Fasciculi longitudinales }\end{array}$ & NTSVO: & $\begin{array}{l}\text { Nucl. tractus spinalis } \mathrm{n} . \\
\text { trigemini oralis }\end{array}$ \\
\hline & pontes & NVII : & Nucl. n. facialis \\
\hline F Rgc : & $\begin{array}{l}\text { The pars gigantocellularis } \\
\text { of the formatio reticularis. }\end{array}$ & $\begin{array}{l}\mathrm{O}: \\
\mathrm{P}:\end{array}$ & $\begin{array}{l}\text { Nucl. olivaris } \\
\text { Nucl. pontis }\end{array}$ \\
\hline FT: & $\begin{array}{l}\text { Fasciculus tegmentalis dorso- } \\
\text { lateralis of Forel (including }\end{array}$ & PCI: & $\begin{array}{l}\text { Pedunculus cerebellaris } \\
\text { inferior }\end{array}$ \\
\hline I C : & $\begin{array}{l}\text { Wallenberg's tract). } \\
\text { Ventral intracommissural }\end{array}$ & PCS : & $\begin{array}{l}\text { Pedunculus cerebellaris } \\
\text { superior }\end{array}$ \\
\hline & bundle & P F : & Nucl. parafascicularis \\
\hline I P : & Nucl. interpeduncularis & $\mathbf{R}:$ & Nucl. ruber \\
\hline L L : & Lemniscus lateralis & RT: & Nucl. reticularis thalami \\
\hline L M: & Lemniscus medialis & $\mathrm{S} N$ : & Sunstantia nigra \\
\hline MD : & $\begin{array}{l}\text { Nucl. medialis dorsalis } \\
\text { thalami }\end{array}$ & $\begin{array}{l}\text { ST: } \\
\text { T P Y : }\end{array}$ & $\begin{array}{l}\text { Nucl. subthalamicus } \\
\text { Tr. pyramidalis }\end{array}$ \\
\hline MM : & $\begin{array}{l}\text { Nucl. medialis corporis } \\
\text { mamillaris }\end{array}$ & $\begin{array}{l}\text { TS : } \\
\text { VEN : }\end{array}$ & $\begin{array}{l}\text { Tr. solitarius } \\
\text { Nuclei ventrales thalami }\end{array}$ \\
\hline MT: & Fasc. mamillothalamicus & Z I : & Zona incerta \\
\hline
\end{tabular}



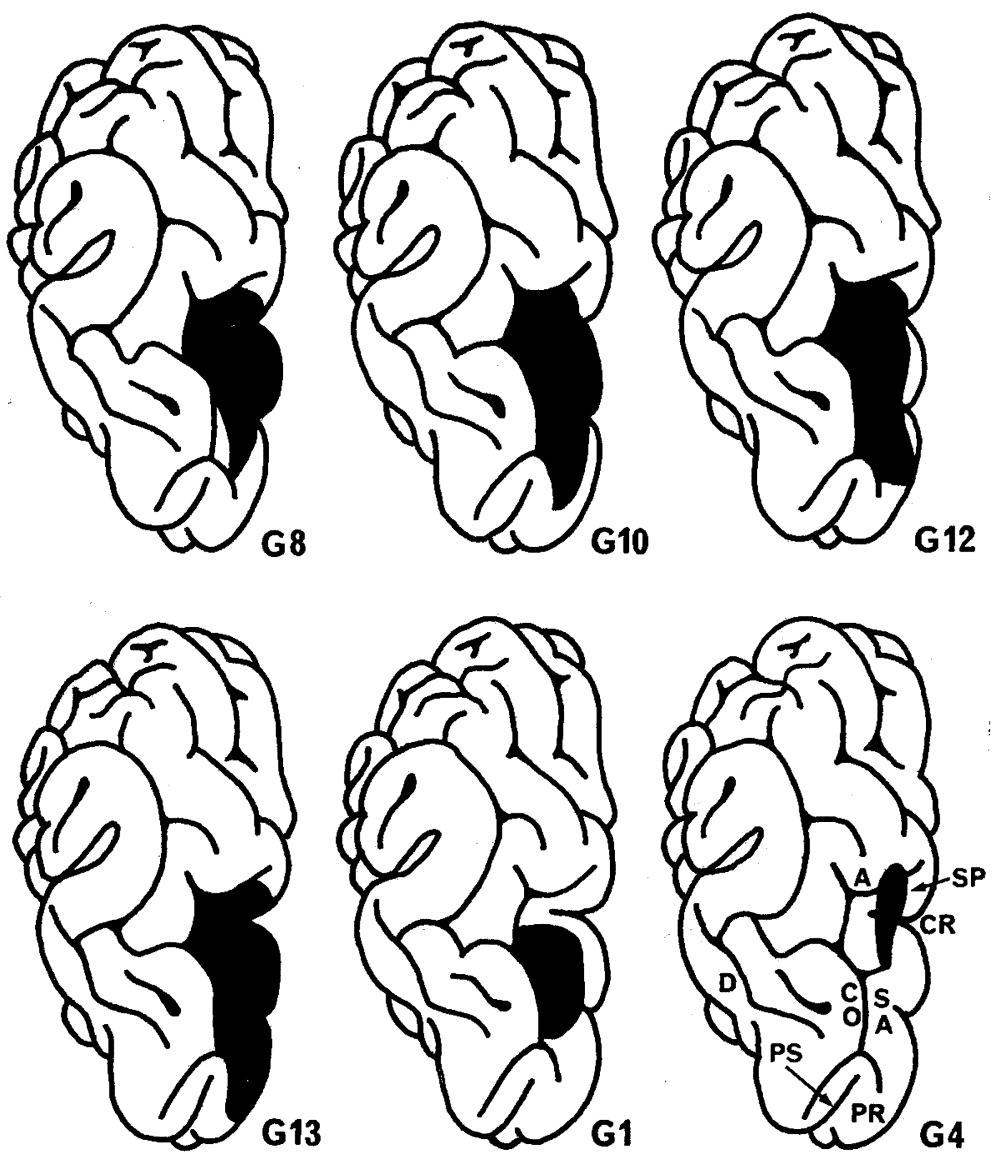

Fig. 1. Semidiagramatic representation of the sites of the lesions of the right hemisphere in goats.

A: Sulc. ansatus $C O$ : Sulc. coronalis $C R$ : Sulc. cruciatus D: Sulc. diagonalis PS: Sulc. presylvius PR: Gyr. proreus SA: Gyr. sigmoideus anterior SP; Gyr. sigmoideus posterior

The pyramidal fibers descended through the medial two-thirds of the peduncle on the same side, but the most medial portion and the lateral third of the peduncle were free from degenerating fibers. In the diencephalon (Fig. 2-A, B), some degenerating fibers separating from the tract entered the zona incerta and several thalamic nuclei dorsomedially through the subthalamic nucleus. The degenerating cortico-thalamic fibers terminated in the ventral part of the thalamic reticular nucleus, the ventral thalamic nuclear group and the nucleus centromedianus. Some preterminal fibers could be found in the parafascicular nucleus.

In the midbrain (Fig. 2-C, D), dense degenerating fibers were located ipsilaterally in the red nucleus and in the reticular formation lateral 
to it. A small number of preterminal fibers were observed in the lateral portion of the periaqueductal gray matter on the same side immediately medial to the dorso-lateral tegmental fascicle of Forel at the transition of the superior and the inferior colliculus. Some terminations were visible in the ipsilateral nucleus of Darkschewitsch.
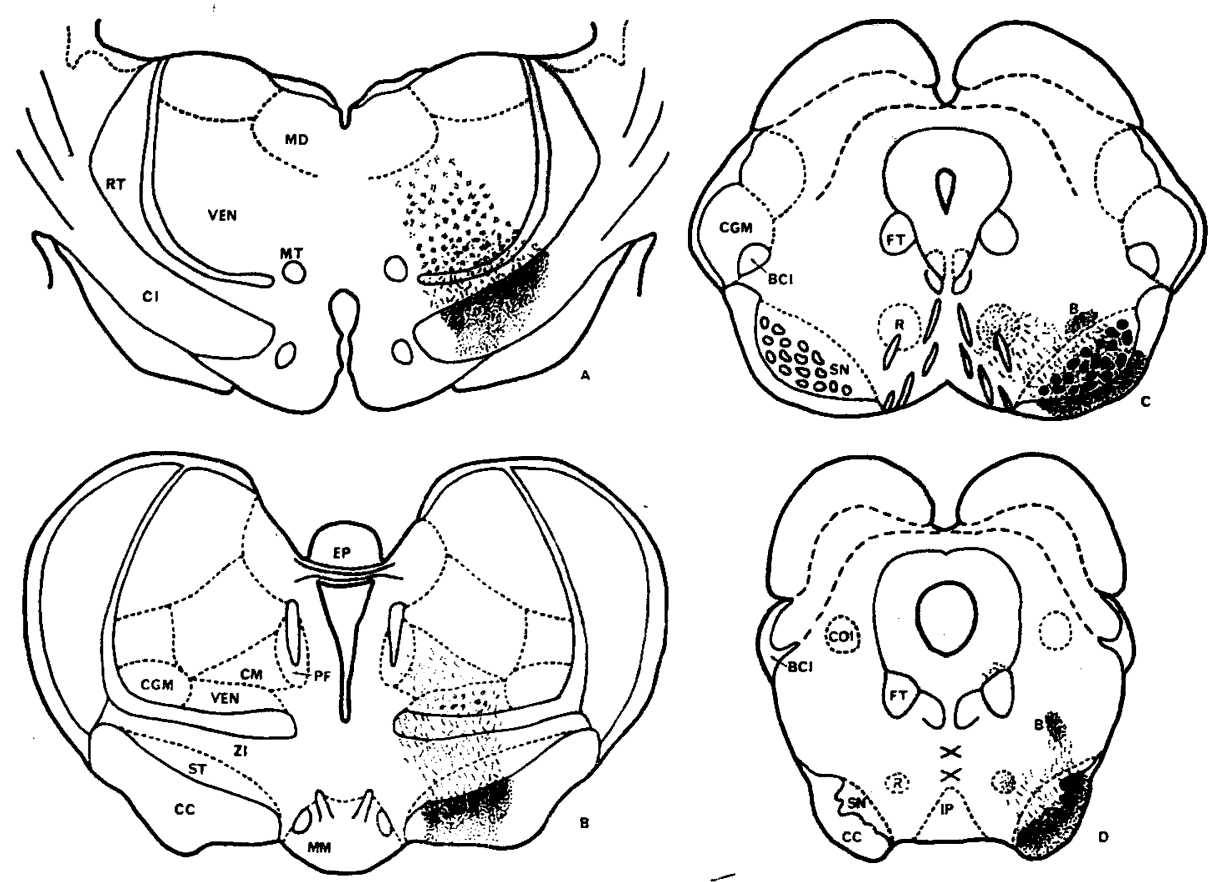

Fig. 2. Transverse sections through the diencephalon and the mesencephalon in goats with sigmoid cortical lesion; degenerated elements are indicated by stipples.

In the upper medulla, a small amount of degenerating fibers was observed in the ventral region of the gigantocellular-portion of the medial reticular formation (Fig. 3-G). Few degenerating fibers were also found to proceed to the contralateral tegmentum.

After the pyramidal decussation (Fig. 3-J), the tract sent preterminal fibers bilaterally to the posterior funicular nuclei (Figs. 5 and 6) and the gray matter just ventral to the nuclei. The remaining fibers descended further down to the spinal cord (Fig. 4). In the descending pyramidal fibers, the degeneration in ventral intracommissural bundles (Fig. 8) were traced at least to the third cervical segment and a very few degenerating fibers could be seen in the nucleus proprius cornu posterioris and the nucleus reticularis spinalis as far as the second cervical cord. Most of the pyramidal fibers decussated to the contralateral side of the cord. 

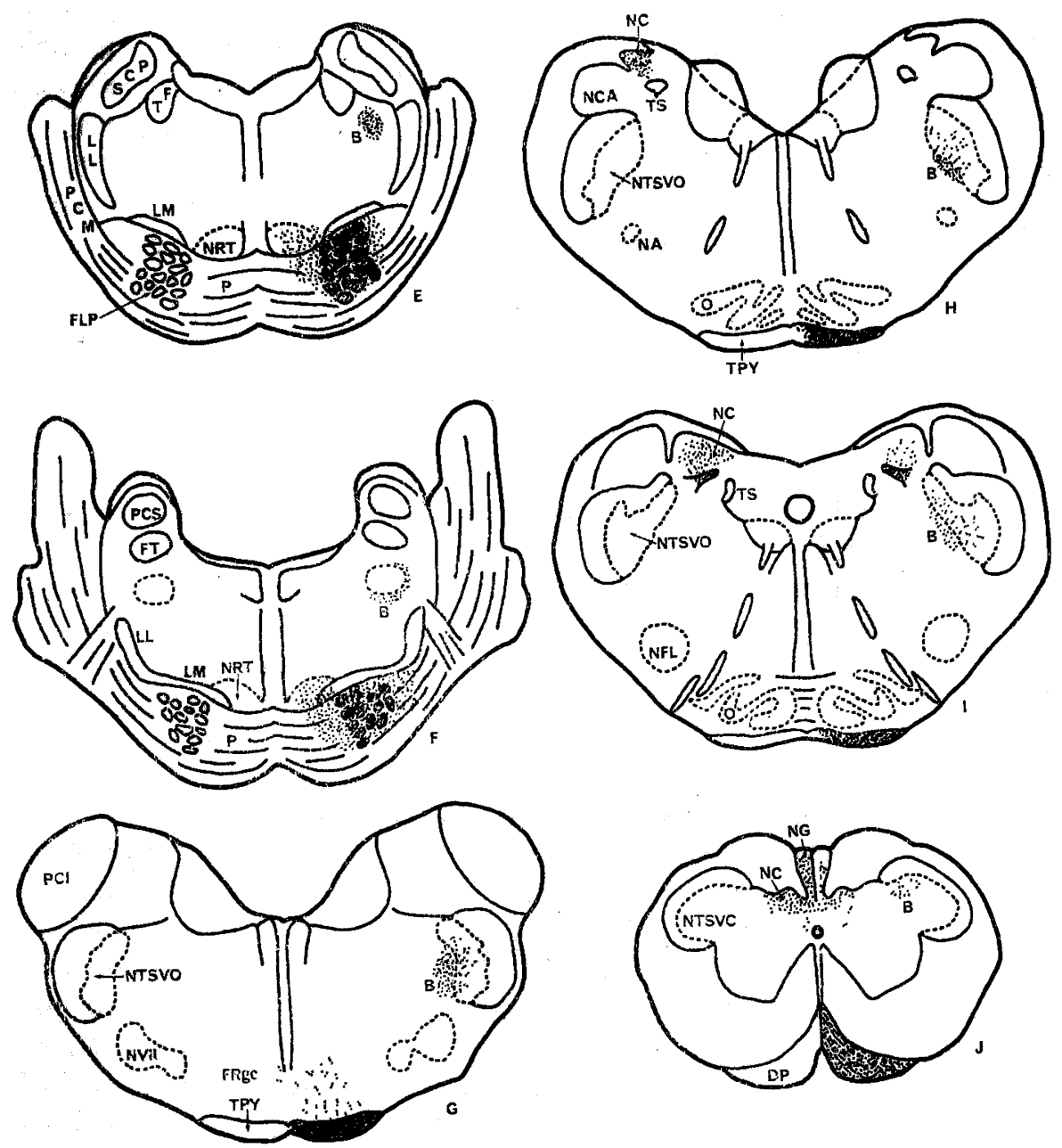

Fig. 3. Transverse sections through the pons and the lower medulla in goats with sigmoid cortical lesion; degenerated elements are indicated by stipples.
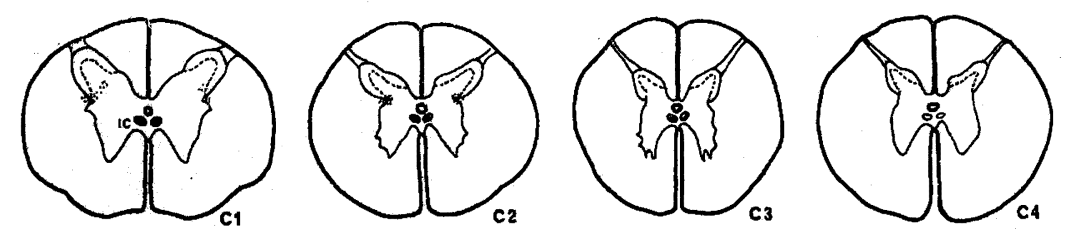

Fig. 4. Degeneration pattern in the upper cervical cord in goats with sigmoid cortical lesion; degenerated elements are indicated by stipples. 
Bundle of Bagley: At most rostral midbrain levels, some degenerating fibers which left the crus cerebri on the same side gathered on the dorsal border of the substantia nigra. This group of fibers soon turned dorsolaterally in the mesencephalic reticular formation and formed a distinct fiber bundle designated as the Bagley's tract (Fig. 2-C, D). Subsequently, the tract ran caudally through the pontine tegmentum between the dorso-lateral tegmental fascicle of Forel and the lateral lemniscus. At the level of the facial nerve nucleus, the degenerating fibers passed through the vicinity of the ventral part of the trigeminal motor nucleus and through the just dorsolateral border of the facial nerve nucleus. However, there were no preterminal degenerating fibers in these two cranial nerve nuclei. The fibers of Bagley's tract descended between the nucleus of the trigeminal tract and the reticular formation just medial to the nucleus and terminated ipsilaterally in the rostral part of the magnocellular subnucleus of the caudal and the oral trigeminal spinal tract nucleus ${ }^{6}$ (Fig. 7). There was no shifting of the fibers dorsally toward the posterior funicular nuclei on the same side to intermingle with the uncrossed pyramidal fibers. Moreover, no degenerating fibers were discernible in the lateral funicular nucleus.

At levels caudal to the pyramidal decussation, few degenerating Bagley's fibers of passage and preterminals were observed in the nucleus of the trigeminal spinal tract.

\section{Discussion}

As for the course and destination of the pyramidal tract at medullary and spinal levels, the present findings agree with previous reports ${ }^{3,4,6,8}$. We confirmed the projection from the sigmoid gyri to the red nucleus that has been described in the rhesus monkey ${ }^{10)}$, cat ${ }^{11}$ and opossum ${ }^{12}$. It has also been reported in the monkey ${ }^{10)}$, cat ${ }^{2)}$ and some animals with lissencephalic brains ${ }^{12,14}$ that the sensori-motor cortex projects to the midbrain central gray substance. In this study, a small number of preterminal fibers could be observed in the lateral portion of the periaqueductal gray at the transition of the superior and the inferior colliculus.

Bagley $^{3)}$ is the first who described a cortico-tegmental tract in the sheep, running caudally through tegmentum to the level of the facial nerve nucleus after leaving the ipsilateral cerebral peduncle. King ${ }^{8}$ didn't find such degenerating fiber bundle in his Marchi study. Dexler and his coworkers", in their investigation of the midbrain after extripation of a large part of a hemisphere, mentioned that a small group of fine degeneration turned laterally and dorsally in the midbrain and disappeared more caudally. However, they failed to identify the de- 
generating fibers as corticofugal ones, because of the great area of softening of the thalamic nuclei which followed their cortical removals.

The course of the Bagley's tract revealed in our study was partially consonant with that of Haartsen et al. ${ }^{5)}$, except for several terminations. It may be suggested that the cortical distributions to the posterior funicular nuclei are supplied with the ascending recurrent pyramidal tract alone which has been reported in the cat ${ }^{98}$, since no degenerating Bagley's fibers proceeded more dorsally beyond the trigeminal spinal tract nucleus to join with the direct pyramidal fibers.

In the atlas of the goat forebrain ${ }^{15 ?}$ and Yoshikawa's atlas ${ }^{19)}$ of the horse, cattle and pig, it seems likely that the fiber bundle depicted and named rubro-spinal tract and fasciculus $Q$ (Sano), respectively, may correspond to the bundle of Bagley.

On the basis of the electrophysiological experiments, Adrian ${ }^{1)}$ mapped out the areas of the cerebral hemisphere receiving the ipsilateral afferent impulses from the snout and lips in the goat, sheep and other animals. Woolsey et al ${ }^{18}$ also demonstrated the ipsilateral face area I receiving impulses from lips, side of face, tongue and floor of mouth in the brains of the pig and sheep. It occupied a considerable wide area surrounding the diagonal sulcus and lay adjacent to the rostral part of the somatic face area I. According to Haartsen et al..$^{5}$, the bundle of Bagley arises from (1) the ontire sigmoid gyri, (2) the rostral fourth and (3) the occipital fourth of the coronal gyrus. Assuming that the somatotopical organization in the sensori-motor cortex in the goat is the same as that in the pig and sheep $p^{18)}$, these aforementioned three cortical areas may correspond to (1) the intermingled area of somatic I with motor area, (2) a part of the contralateral face area I and (3) a part of the ipsilateral face area I, respectively. Karamanlidis et al..$^{6}$ concluded that the oral part of the nucleus of the trigeminal spinal tract and a part of the principal sensory nucleus projected ipsilaterally to the medial part of the nucleus ventralis posterior thalami through the Wallenberg's dorsal sensory trigeminal tract ${ }^{16)}$. That is to say, the somatic area $I$ in the goat is connected indirectly with the trigeminal sensory nuclei by the ipsilateral ascending pathway relaying in the ventral posterior thalamic nucleus. On the other hand, the sensori-motor cortex including somatic area I emits Bagley's fibers directly to the trigeminal sensory nuclei on the same side. Since the Bagley's bundle arises not only from the ipsilateral face area I but also from the entire somatic I and motor cortices, the bundle may deal with the ipsilateral feedback system, but it may more importantly participate in the transmission of modified somatosensory informations, which are sent from the contralateral side of the body, to the trigeminal sensory nuclei of the same side.

It is conceivable that the goat brain develops the central fiber 
connections advantageous for his feeding behavior ${ }^{1)}$ which depends mainly on olfaction rather than sight. There is no crossing of the olfactory fibers and passages from the receptors in the big nostril and lips of the animals go to the cerebral hemisphere on the same side.

\section{Summary}

The cortical projection fibers were studied with the Nauta-Gygax method on six goats after sigmoid cortical ablations.

Pyramidal tract: Cortico-thalamic fibers terminated ipsilaterally in the ventral thalamic nuclear group, the centre median and parafascicular nuclear complex and a part of the thalamic reticular nucleus. In the midbrain, considerable preterminal fibers were found in the red nucleus and the lateral part of the central gray matter.

The ventral part of the gigantocellular region of the medial reticular formation in the upper medulla received a small number of cortical fibers.

After pyramidal crossing, some of the fibers terminated in the posterior funicular nuclei, and remaining fibers were traced predominantly through the ventral intracommissural bundles as far as the third cervical segment and less prominently through the nuclei proprius posterioris and reticularis spinalis down to the second cervical cord.

Bagley's bundle: At the most rostral end of midbrain, many degenerating fibers left the ipsilateral cerebral peduncle to gather on the dorsal border of the substantia nigra. The discrete bundle ran more caudally through the dorso-lateral tegmentum to the medulla and was distributed ipsilaterally to the rostral part of the magnocellular subnucleus of the caudal and the oral trigeminal spinal tract nucleus.

\section{Acknowledgements}

The authors wish to express their appreciation to Mr. Kazuo Miyama for the photomicrography and the neurosurgical assistance and to Mrs. Fumiyo Saito for her histological preparations. Critical reading of the manuscript by Dr. Hiroharu Noda; Brain Research Institute, University of California, is also gratefully acknowledged.

\section{References}

1) Adrian, E.D.: Afferent areas in the brain of ungulates. Brain, $66: 89-103,1943$

2) Akiba, H.: Projections from the sensory motor cortex to the subcortical nuclei superior to the mesencephalic level in cats. J. Chiba med. Soc., 36:688-709, 1960 (in Japanese)

3) Bagley, C. Jr.: Cortical motor mechanism of the sheep brain. Arch. Neurol. Psychiat. (Chic.), 7: 417-453, 1922 
4) Dexler, H. and Margulies, A.: Über die Pyramidenbahn des Schafes und der Ziege. Z. Anat. Entwickl.-Gesch., 35:413-449, 1906

5) Haartsen, A.B. and Verhaart, W. J.C.: Cortical projections to brain stem and spinal cord in the goat by way of the pyramidal tract and the bundle of Bagley. J. Comp. Neur., 129 : 189-202, 1967

6) Karamanlidis, A. N. and Voogd, J. : Trigemino-thalamic fibre connections in the goat. An experimental anatomical study. Acta anat. (Base1), 75:596-622, 1970

7) King, J. L.: Localisation of the motor area in the sheep's brain by the histological method. J. Comp. Neur., $21: 311-321,1911$

8) King, J.L.: The pyramidal tract and other descending paths in the spinal cord of the sheep. Quart. J. Exp. Physiol., 4: 133-150, 1911

9) Kuypers, H.G. J.M. : An anatomical analysis of cortico-bulbar connexions to the pons and lower brain stem in the cat. J. Anat. (Lond.), 92: 198-218, 1958

10) Kuypers, H.G. J.M. and Lawrence, D. G. : Cortical projections to the red nucleus and the brain stem in the rhesus monkey. Brain Research, $4: 151-188,1967$

11) Mabuchi, M. and Kusama, T.: The cortico-rubral projection in the cat. Ibid., 2: 254-273, 1966

12) Martin, G.F.Jr. : The pattern of neocortical projections to the mesencepbalon of the opossum, Didelphis virginiana. Ibid., 11:593-610, 1968

13) Nauta, W.J.H. and Gygax, P.A.: Silver impregnation of degenerating axons in the central nervous system: A modified technic. Stain Technol., 29: 91-93, 1954

14) Shriver, J.E. and Noback, C.R.: Cortical projections to the lower brain stem and spinal cord in the tree shrew (Tupaia glis). J. Comp. Neur., 130: 25-54, 1967

15) Tindal, J.S., Knaggs, G.S. and Turvey, A.: The forebrain of the goat in stereotaxic coordinates. J. Anat. (Lond.), 103:457-469, 1968

16) Verhaart, W.J.C. and Busch, H.F.M.: Wallenberg's tract, the fasciculus tegmentalis dorso-lateralis and Forel's fasciculi tegmentales. Acta anat. (Basel), $40: 41-58,1960$

17) Verhaart, W.J.C.: Comparative anatomical aspects of the mammalian brain stem and the cord. Vol. 1-Text, Van Gorcum, Assen, 182-207, 214-234, 1970

18) Woolsey, C. N. and Fairman, D. : Contralateral, ipsilateral, and bilateral representation of cutaneous receptors in somatic area I and II of the cerebral cortex of pig, sheep, and other mammals. Surgery, 19:684-702, 1946

19) Yoshikawa, T.: Atlas of the brains of domestic animals. University of Tokyo Press, Tokyo, H 11-H 18, C 13 and P 11, 1967 


\section{Explanation of Figures}

\section{Plate I}

Figs. 5-7. Preterminal degenerating fibers in various nuclei following ablation of the sigmoid gyri in goats. Photomicrographs of the Nauta-Gygax preparations.

Fig. 5. The contralateral cuneate nucleus. $(\times 100)$

Fig. 6. The ipsilateral cuneate nucleus. $(x 100)$

Fig. 7. The oral part of the nucleus of the trigeminal spinal tract. $(\times 100)$

Fig. 8. The ventral intracommissural bundle, containing degenerating pyramidal fibers, in the commissura alba at the first cervical segment. Transverse section. $(\times 100)$

CL: The contralateral side

IL: The ipsilateral side 


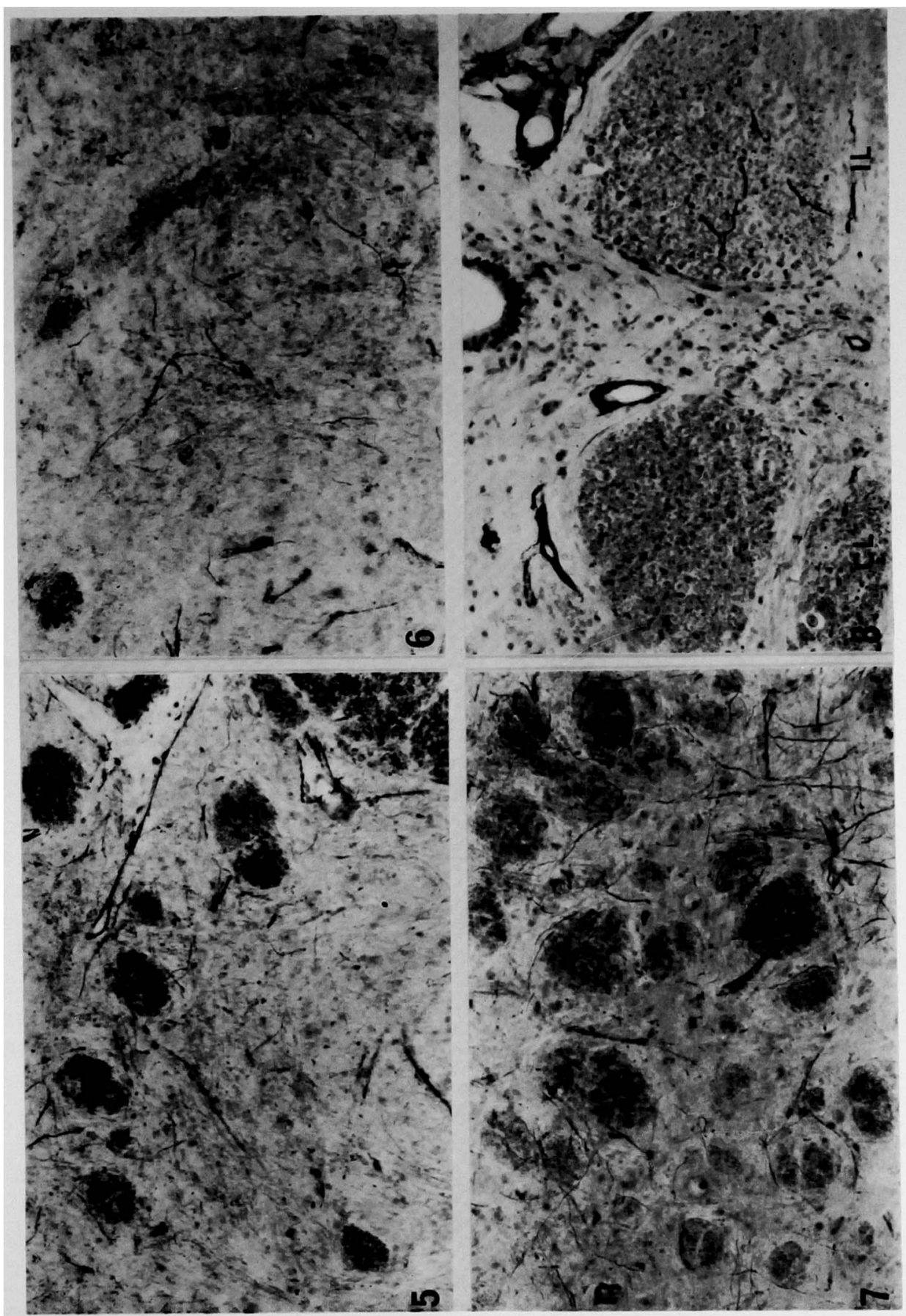

